International Journal of Library \& Information Science (IJLIS)

Volume 8, Issue 3, September - December 2019, pp. 1-6, Article ID: IJLIS_08_03_001

Available online at

http://iaeme.com/Home/issue/IJLIS?Volume $=8 \&$ Issue $=3$

Journal Impact Factor (2019): 9.8614 (Calculated by GISI) www.jifactor.com

ISSN Print: 2277-3533 and ISSN Online: 2277-3584

(C) IAEME Publication

\title{
HUMANITIES RESEARCH IN KERALA: AN OVERVIEW
}

\author{
Suguna.L.S. \\ Research Scholar, Dept. of Library \& Information Science \\ University of Kerala, India
}

\begin{abstract}
Humanities refer to the branches of learning concerned with the human thought, feelings and relations. They are very important in our lives. The present study deals with analyzing Humanities research in Kerala. Quantitative methods such as bibliometrics have the potential to offer a fresh perspective on humanities research, its characteristics, structure, practices, habits, outcomes, and processes. Collected data was analyzed using descriptive statistical method. The study assumes significance in the context of declining interest in the subjects coming under the preview of Humanities.
\end{abstract}

Key words: Humanities; Research; Kerala

Cite this Article: Suguna.L.S., Humanities Research in Kerala: An Overview, International Journal of Library \& Information Science, 8(3), 2019, pp. 1-6.

$\mathrm{http}: / /$ iaeme.com/Home/issue/IJLIS?Volume $=8 \&$ Issue $=3$

\section{INTRODUCTION}

Research is the search for knowledge, or as any systematic investigation, with an open mind, to establish novel facts, usually using a scientific method. The primary purpose of research is discovering, interpreting, and the development of methods and systems for the advancement of human knowledge on a wide variety of matters of our world and the universe.

Batty (2019) discussed how doctoral candidates identify and navigate personal learning challenges on their journey to becoming researchers. They asked humanities candidates and creative arts to think beyond the research project itself and reflect on emotional hurdles they were facing or had overcome. The findings point to a great deal of 'invisible' work that underpins doctoral study, and show that such hidden work can have a major influence not only on the research project, but also on progress and satisfaction with the learning journey. The study outlines the emotional and transformational dimensions of the doctoral journey.

Ferrini (2015) introduced research values in the Humanities. The study examined the trends, risks, needs, pressures, and prospects of the humanities after recent education reforms throughout Europe. The study focus on the educational, cultural, and social value of research in the humanities, which also provide economic and democratic benefits, this special issue 
focuses on three key topics: "funding policies", "evaluation", and "cultural resources". The author gave reflects on the controversial issues of quality control, measures of research productivity, and funding decisions as key drivers changing the humanities. She gives an overview of the current difficulties and prospects for "modernizing" the humanities.

Burrows (2008) measured the participation of Humanities researchers in building a national digital repository of Humanities Research outputs in Australia. The study offers a unique opportunity to develop scholarly communication and the dissemination of research. The main emphasis is on transforming the way in which researchers communicate within a well established Humanities discipline, and on fostering the kind of cultural change that will be a necessary part of this transformation. The main goal of the project is to promote communication between researchers at national, discipline based level, with the help of a wide range of information technologies. This will encourage them to collaborate across institutional and disciplinary boundaries.

In India also, the hard core scientific institutions like Indian institutes of Technology have started offering courses and research programmes in humanities, realizing their importance in a civic society. The review of related studies revealed the fact that a lot of research related to bibliometric study of Humanities is carried out in foreign countries than in India. The study based on research contributions is very much useful to assess the development of Humanities as well as their application in the field of Library and Information Science.

\section{RESEARCH INSTITUTIONS}

Research institutions in the field of Humanities that are aimed at research projects, education and public programmes in Kerala are:

- Universities in Kerala

- Central university of Kerala

- Cochin University of Science \& Technology

- Kannur University

- Mahatma Gandhi University

- Sree Sankaracharya University of Sanskrit

- University of Calicut

- University of Kerala

- Kerala Kalamandalam

- Kerala Sahitya Akademi

- Sukrtindra oriental research institute

- Indian institute of Architects Kerala chapter

- Kumaran Asan National Institute of culture

- Prof. N. Krishna Pillai Foundation

- Kunchan Nambiar Smarkam

- Mahakavi Ulloor memorial Library \& Research centre

- Kerala vastuvidya Akademi

- Vastuvidya Gurukulam

- Vastu Academy

- Kerala folklore Akadami

- Sopanam Institute of performing Arts and Research

- Kerala Sangeetha Nataka Akademi 
- Kerala Lalithakala Academi

- Centre for Art reference and Research Ernakulum

- The state Institute of languages

- Vyloppilli Samskriti Bhavan

- Thunchan Memmorial Trust

\section{OBJECTIVES OF THE STUDY}

- To find out the year wise distribution of research.

- To identify the subject wise distribution of research.

- To check the applicability of Lotka's Law.

- To identify the gender wise distribution.

- To estimate the total number of citations

\section{METHODOLOGY}

Methodologies adopted for the study are:

Literature Survey: Periodicals and selected books in the field of library and information science were scanned to get into the depth of the subject.

Bibliometric Analysis: Using various search techniques the researcher checks the research of the humanities subjects.

Informal Communication: An informal communication was done for collecting data directly from some of the research guides and scholars in humanities.

\section{Analysis}

In order to study the research trends in Humanities in Kerala, a total of 2478 researches conducted in Kerala were used as the source.

\section{Gender-wise Distribution of Researchers}

The study of differences in productivity between men and women in the world of research has always attracted interest of a wide range of observers. Many such studies have established the lesser productivity of females of different countries and disciplines. The analysis of the gender wise distribution of the researchers is presented in Table 1.

Table 1 Gender-wise Distribution of Researchers

\begin{tabular}{|c|c|c|}
\hline Male & Female & Total \\
\hline $1383(55.81 \%)$ & $1095(44.19 \%)$ & $2478(100.00)$ \\
\hline
\end{tabular}

\section{Gender-wise Distribution of Research Guides}

The gender-wise distribution of researchers has shown that the disparity is not very wide. In order to see whether it is true of research guides, gender wise analysis was carried out.

Table 2 Gender-wise Distribution of Researcher Guides

\begin{tabular}{|c|c|c|}
\hline Male & Female & Total \\
\hline $421(79.58 \%)$ & $108(20.42 \%)$ & $529(100 \%)$ \\
\hline
\end{tabular}


From the study it is clear that there is significant gender difference in the case of guides. Though there are large numbers of female researchers, the number of female guides is comparatively low.

\section{Decade- wise Distribution of Theses}

Year-wise analysis of theses indicates the progress of research in a field. The year wise distribution of theses is presented here. It shows that there is a high increase in the number of researches in each succeeding decades from 1970 onwards. Succeeding decades showed a twofold increase in the number of theses.

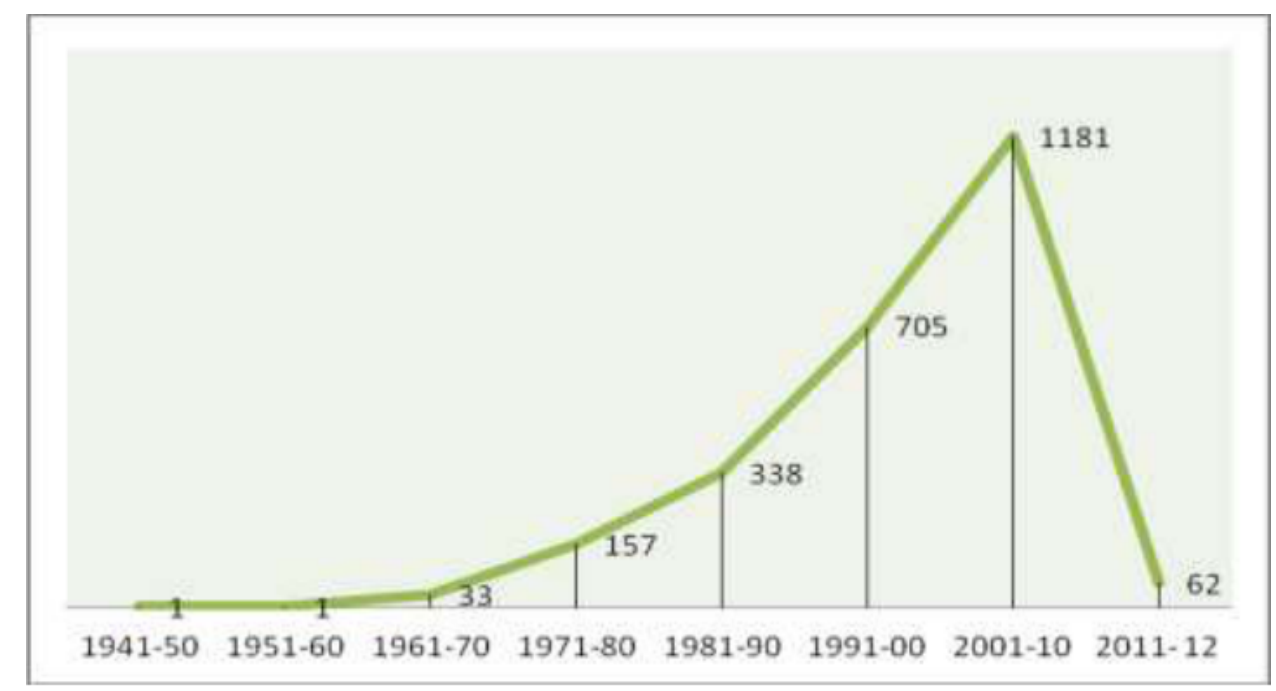

Figure 1

During 1941 - 50 only one research was produced in the field of Humanities. Geethakumari Amma produced the first research in the year 1950 titled "Mannu Bhandarika ka kathasahitya" in Hindi under the guidance of N. Suresh. In the next decade also there was only one thesis. UGC regulations (1956) on minimum qualifications for appointment of teachers and other academic staff in Universities and Colleges bring forth the measures for the maintenance of standards in Higher Education. This is evidently seen in here. During 60's a steady increase in number can be notified with 33 theses. There is a five-fold increase in the number of theses during 1971 - 80 compared to 1961 - 70. During $80 \mathrm{~s}$, the number doubled than that of the previous decade. This doubling trend continued in the next two decades. Nearly fifty percent of the researches were produced during 2001-10.

\section{Subject-wise Distribution of Theses}

As per Colon Classification Scheme Humanities subjects include Useful Arts, Fine Arts including Visual and Performing Arts, Languages and Literature, Linguistics, Religion, Philosophy and Psychology.

From the study it is evident that more than half of the research work is done in Indian languages. Malayalam and Hindi come with maximum number. This is because Malayalam is the mother tongue of the state. Hindi is the national language having much influence in all aspects of the life of Kerala. This is followed by English language and literature. Research work in Fine Arts and Religion is far less. 
Table 3 Subject-wise Distribution

\begin{tabular}{|c|l|c|c|}
\hline Sl. No. & \multicolumn{1}{|c|}{ Subjects } & Frequency & Percentage \\
\hline 1 & English & 482 & 19.45 \\
\hline 2 & Malayalam & 525 & 21.19 \\
\hline 3 & Hindi & 511 & 20.62 \\
\hline 4 & Sanskrit & 202 & 8.15 \\
\hline 5 & Tamil & 160 & 6.46 \\
\hline 6 & Other Languages & 117 & 4.72 \\
\hline 7 & Fine Arts & 63 & 2.54 \\
\hline 9 & Linguistics & 100 & 4.04 \\
\hline 10 & Philosophy & 158 & 6.38 \\
\hline 11 & Psychology & 16 & 5.81 \\
\hline 12 & Religion & 2478 & 0.64 \\
\hline Total & & & 100 \\
\hline
\end{tabular}

\section{Most Commonly Used Citation Style}

A citation is a way of giving credit to individuals for their creative and intellectual works that is utilized to support the research and can also be used to locate particular sources and combat plagiarism The citation style researchers choose will largely be dictated by the discipline in which they writing, and for most assignments their instructor will assign a style to them. For example:

- APA (American Psychological Association) is used by Education and Sciences.

- MLA (Modern Language Association) style is used by the Humanities

- Chicago style is generally used by Business, History, etc.

Table 4 Most Commonly Used Citation Style

\begin{tabular}{|c|l|c|c|}
\hline Sl. No. & \multicolumn{1}{|c|}{ Style } & Count & Percent \\
\hline 1 & No style & 162 & 6.5 \\
\hline 2 & APA & 297 & 12.0 \\
\hline 3 & Chicago & 1427 & 57.6 \\
\hline 4 & MLA & 592 & 23.9 \\
\hline Total & 2478 & 100 \\
\hline
\end{tabular}

From the study it is evident that Chicago is the most commonly used citation style in humanities research followed by MLA style. Least commonly used style is APA style.

\section{Inter disciplinary and Multidisciplinary Research}

Inter disciplinary research has become an increasingly common method of study in education. Inter disciplinary research is a type of study that draws from two disciplines in order to gain a more well developed perspective or discover something new. A Multidisciplinary approach involves drawing appropriately from multiple academic disciples to redefine problems outside normal boundaries and reach solutions based on a new understanding of complex situations. Based on the subject analysis, one can analyze the combination of disciples that has come to the research topic or title. 
Suguna.L.S.

Table 5 Trend in Humanities Research

\begin{tabular}{|c|l|c|c|}
\hline Sl.No. & \multicolumn{1}{|c|}{ Thesis } & No. of theseis & Percentage \\
\hline 1 & Single discipline & 1908 & $77 \%$ \\
\hline 2 & Interdisciplinary & 545 & $22 \%$ \\
\hline 3 & multidisciplinary & 25 & $1 \%$ \\
\hline Total & & 2478 & $100 \%$ \\
\hline
\end{tabular}

\section{Productivity of research guides using Lotka's Law}

Lotka's law describes the frequency of publication by authors in any given field. It states that the number of authors making contributions in a given period is a fraction of the number making a single contribution. There is a scope for productivity analysis of research guides in the field of humanities using Lotka's law. It shows the frequency distribution of productivity. Here in Table 5 the number of guides against the number of contributions made by them.

Table 6 Productivity of research guides

\begin{tabular}{|c|c|c|}
\hline Sl. No. & No. of theses & Number of guides \\
\hline 1 & $1-5$ & $408(77.13)$ \\
\hline 2 & $6-10$ & $83(15.68)$ \\
\hline 3 & $11-15$ & $24(4.54)$ \\
\hline 4 & $16-20$ & $8(1.51)$ \\
\hline 5 & $21-25$ & $4(0.76)$ \\
\hline 6 & $25-30$ & $2(0.38)$ \\
\hline \multicolumn{2}{|c|}{ Total } & $529(100)$ \\
\hline
\end{tabular}

Lotka's Law can be applied reasonably in humanities. As the number of articles published increases, authors producing that many publications become less frequent. Generally, Lotka's Law is an inverse square law that for every 100 authors contributing one article, 25 will contribute 2, 11 will contribute 3 , and 6 will contribute 4 each. A general performance among a body of authors follows $1: \mathrm{n}^{2}$. In the above table this is not exactly followed but holds true as the number of theses published increases, guides producing that many theses become less frequent.

\section{CONCLUSION}

The study emphasized the perspective of the research activities in Kerala in the field of Humanities. In Kerala there has been a perceptible increase in the quantum of research work in the fields coming under the purview of Humanities. Humanities scholars explore ethical issues, and discover how the past informs the present and the future. They learn to decode the images that surround us and try to understand and use the language necessary to navigate a complex and rapidly shifting world.

\section{REFERENCES}

[1] Batty, C., Elizabeth, E., \& Owens, A. (2019). Mapping the emotional journey of the doctoral 'hero': Challenges faced and breakthroughs made by creative arts and humanities candidates. Arts and Humanities in Higher Education.

[2] Burrows, T. (2008). Developing a digital repository for a humanities research network. New review of academic librarianship, 13(1), 1-11.

[3] Ferrini, C. (2015). Research "Values" in the Humanities: Funding Policies, Evaluation, and Cultural Resources. Some Introductory Remarks. Humanities. , 4 (1), $42-67$. 